\title{
CRÉDITO JUVENIL: A CONSTRUÇÃO SOCIAL DA JUVENTUDE RURAL MODERNA
}

Joel Orlando Bevilaqua Marin ${ }^{1}$

\begin{abstract}
RESUMO
O artigo analisa processos de construção social da juventude rural moderna a partir de uma experiência pioneira de crédito agrícola para jovens rurais, instituída no final da década de 1950. Os dados da pesquisa foram obtidos pela combinação de pesquisa documental e bibliográfica. O Crédito Juvenil, articulado com os serviços de extensão rural e os clubes de jovens rurais, foi um instrumento para inserção da juventude rural nos processos de modernização da agricultura brasileira e para a produção de referências modelares para jovens rurais modernos. Conclui-se que a política de crédito agrícola para jovens foi um investimento para a construção social de uma juventude rural moderna no Brasil.
\end{abstract}

Palavras-chave: crédito juvenil, crédito rural, extensão rural, juventude rural.

\section{YOUTH CREDIT: SOCIAL CONSTRUCTION OF MODERN RURAL YOUTH}

\begin{abstract}
This article analyzes the processes of social construction of modern rural youth from a pioneering experience of agricultural credit to rural youth, instituted in the late 1950s. The research data were obtained by combining documentary and bibliographic research. Youth Credit, articulated with rural extension services and rural youth clubs, was an instrument for the insertion of rural youth in the processes of modernization of Brazilian agriculture and for the production of reference models for modern rural youth. We conclude that the agricultural credit policy for young people was an investment for the social construction of a modern rural youth in Brazil.
\end{abstract}

Keywords: rural credit, rural extension, rural youth, youth credit.

\section{INTRODUÇÃO}

O Crédito Juvenil, instituído pelo governo brasileiro, tinha como propósito integrar as gerações juvenis rurais nos processos modernização da agricultura experimentados no Brasil a partir da segunda metade do século XX. O programa de crédito também buscava produzir o reconhecimento público e a inserção da

1 Graduação em Veterinária (UFSM). Mestrado em Extensão Rural (UFSM). Doutorado em Sociologia (UNESP). Professor do Programa de Pós-Graduação em Extensão Rural (PPGExR) da Universidade Federal de Santa Maria (UFSM). E-mail: bevilaquamarin@gmail.com. 
juventude rural em instituições de desenvolvimento rural. A juventude rural moderna é aqui entendida como um constructo histórico-social, objetivado pela criação de instituições de socialização e de políticas públicas, especificamente destinadas à formação de jovens rurais qualificados para a adoção de tecnologias, procedimentos e ideias, então considerados necessários para modernizar a agricultura e promover o desenvolvimento rural. Com esse entendimento, tomo como ponto de partida a política de Crédito Juvenil para analisar investimentos para o enquadramento institucional da juventude rural e a formação de jovens rurais adequados à modernização da agricultura, como processos integrantes da construção social da juventude rural moderna.

Para a análise da experiência de institucionalização do Crédito Juvenil, recorri à pesquisa documental. Os documentos consultados foram primordialmente produzidos pela Associação Brasileira de Crédito e Assistência Rural (ABCAR), instituição oficial de extensão rural incumbida pela objetivação da política de Crédito Juvenil no contexto da modernização da agricultura brasileira. Como orienta Cellard (2010, p. 296), na análise documental, o pesquisador deve levar em consideração o contexto em que os documentos foram produzidos, os autores e os atores sociais que estão em cena, a confiabilidade do documento e sua natureza e lógica interna, a fim de compreender adequadamente o sentido das mensagens contidas nos documentos escritos. Para o autor, os documentos produzidos estão vinculados a uma realidade ou campos de ação que socialmente se buscam construir ou reproduzir e, portanto, não podem ser considerados meros dados e informações, sem intenções ou interesses sociais. Dessa forma, considerando que os documentos analisados foram produzidos por instituições encarregadas por um projeto de educação para o capital (FONSECA, 1986), procurei compreender, nas formas de objetivação da política de Crédito Juvenil, os processos de construção social de modelos ideais para a juventude rural no contexto de modernização da agricultura.

Os dados obtidos nas fontes documentais foram cotejados com o conhecimento teórico produzido sobre a juventude rural e o desenvolvimento rural. Dessa forma, a compreensão de processos de construção social da juventude rural moderna, visados no escopo da política de Crédito Juvenil, resultou do esforço da triangulação da análise documental e da pesquisa bibliográfica.

$\mathrm{O}$ artigo divide-se em três seções interconectadas, além dessa introdução e das considerações finais. Inicialmente, procuro compreender os investimentos para institucionalização da política pioneira de crédito para os jovens rurais no contexto da modernização da agricultura. Em sequência, analiso a normatização do crédito juvenil como uma estratégia de construção de uma juventude moderna e organizada sob a tutelada dos agentes de desenvolvimento rural. Por fim, estudo a relação entre a política de crédito agrícola juvenil e a produção de modelos ideais para a juventude rural.

\section{CRÉdITO JUVENIL, JUVENTUde RURAL E MODERNIZAÇÃo DA AGRICULTURA}

Crédito juvenil foi a designação da primeira modalidade de crédito financeiro destinado especificamente para a juventude rural no Brasil, instituído no fim da década de 1950, quando o Estado criava diversos programas e políticas de modernização da agricultura. Nesse contexto, a juventude rural tornou-se questão de debate público, que envolveu diversos agentes sociais vinculados às organizações internacionais, representantes do poder público, empresários, técnicos de desenvolvimento rural, professores rurais, lideranças comunitárias e, 
evidentemente, jovens rurais.

No bojo dessa problematização, surgiram propostas de organizar a juventude em clubes rurais e disponibilizar o crédito rural a fim de que os jovens rurais pudessem experimentar novas tecnologias e novas formas de administração da propriedade e do lar. Os diversos agentes sociais comprometidos com a concretização desse projeto de modernização da agricultura apontavam para a necessidade de promover mudanças nas bases tecnológicas e nas mentalidades das populações rurais. Os jovens rurais foram, então, percebidos como catalisadores de tais mudanças sociais, o que justificava os esforços na institucionalização de políticas de crédito rural. Os jovens rurais foram inseridos em instituições modernizadoras da agricultura para colaborar nos projetos orientados para o aumento da produção e produtividade da agricultura e melhoria das condições de vida da população rural.

A juventude tem sido percebida como uma fase do ciclo da vida das pessoas, compreendida entre a infância e a vida adulta. Mas, muito além de uma etapa da vida das pessoas, a juventude deve ser entendida como uma construção social, na medida em que as sociedades, em diferentes tempos históricos e espaços geográficos, produziram distintos espaços, concepções e simbologias para assinalar os limites das fronteiras entre as idades. De acordo com Bourdieu (1983), as divisões entre as idades são fenômenos sociais definidos a partir de certos critérios arbitrários e manipuláveis, cujas representações ideológicas sobre as diferentes idades da vida sempre foram questões de disputas sociais, uma vez que implica na apropriação de poderes e recursos sociais. O autor também destaca que a construção social da juventude está relacionada com a criação de instituições destinadas à socialização dos jovens, notadamente, as escolas. Por tais caminhos analíticos, a juventude é compreendida como uma categoria relacional, o que implica o estudo dos contextos históricos e socioeconômicos em que os jovens vivem, em suas múltiplas interrelações com classe social, família, gênero, vinculações laborais e escolares, dentre outros aspectos da vida em sociedade.

Em perspectiva analítica semelhante, Feixa (1993) também compreende a juventude como um constructo histórico-social. Essa propositura analítica enfoca a juventude não a partir de uma suposta natureza ou essência, mas pela compreensão dos contextos econômicos, sociais e culturais em que os jovens estão inseridos (FEIXA, 2004). Para o autor, os conteúdos da construção social são frutos das inter-relações entre as condições sociais e as imagens culturais que cada sociedade ou grupo social elabora acerca da juventude. As condições sociais, segundo Feixa (2006), evidenciam as situações estruturais em que os jovens estão inseridos, ao passo que as imagens culturais constituem as elaborações subjetivas, que são produzidas pelas instituições que intervêm na questão juvenil ou mesmo pelos próprios jovens. Contudo, as condições sociais e as imagens juvenis não são neutras, mas dotadas de interesses, de conflitos e adaptações entre os projetos e discursos institucionais e as elaborações e aspirações dos jovens.

Sob esse prisma teórico-metodológico, a construção social da juventude rural representou um investimento na formação de uma geração de jovens rurais qualificados para atuar em uma sociedade capitalista, ditada pelas trocas mercantis. Vale lembrar que a modernização da agricultura designa as transformações nas bases tecnológicas para aumentar a produção e a produtividade agropecuária para o atendimento mercado interno e externo. Desencadeada no período pós-guerra, a modernização da agricultura representou o aprofundamento das inter-relações entre a agricultura e os setores industriais, financeiros, comerciais e de serviços, com o aumento das trocas de produtos, recursos financeiros e serviços (GRAZIANO DA SILVA, 1998) sob forte intervenção do Estado e controle social, especialmente, 
sobre as classes trabalhadoras do campo (SORJ, 1980). Os diferenciados instrumentos de políticas agrícolas foram fundamentais na "construção do produtor moderno" (NEVES, 1987), que passou a usar novas tecnologias e novos conhecimentos e se inserir em relações mercantis. Assim, a modernização da agricultura engendrou um "novo agricultor", o agricultor moderno, adequado à lógica da sociedade industrial. As gerações juvenis do espaço agrário também foram inseridas nesses processos de transformação social.

Para realizar a modernização agrícola, o Estado brasileiro instituiu um conjunto de políticas (NETO, 1997) dentre as quais, para efeitos desta pesquisa, destaco o crédito rural e a extensão rural. Na realidade, o crédito rural e a extensão rural interligavam-se de maneira que um instrumento potencializava e dava sentido ao outro. A modalidade de crédito rural, instituída na década de 1950, recebeu a designação de supervisionada ${ }^{2}$, que, segundo Machado e Ribeiro (1960), já havia sido experimentada nos Estados Unidos enquanto estratégia de superação da crise econômica de 1929, cujos recursos financeiros deviam ser destinados à produção agrícola e à melhoria de condições de vida dos agricultores sob a supervisão técnica e administrativa dos extensionistas rurais. De acordo com Fonseca (1986), Oliveira (1999) e Seiffert (1987), o crédito rural supervisionado foi transplantado no Brasil, juntamente com os programas de extensão rural, por ingerência de organismos internacionais comprometidos com a expansão das influências econômicas, políticas, culturais e ideológicas, por meio dos processos de modernização da agricultura.

O Crédito Rural Supervisionado, instituído em 1948, atendia, fundamentalmente, pequenos produtores pela conjugação dos serviços de crédito e de extensão rural, com propósitos de suprir as despesas de investimentos e custeio tanto nas atividades agrícolas quanto de economia doméstica para melhorar as condições de habitação, alimentação, saúde, educação e vestuário (RODRIGUES, 1997). Inicialmente, a extensão e o crédito rural supervisionado objetivaram o enquadramento dos membros adultos da família: o homem, como chefe de família, para aumentar a produção e produtividade do empreendimento familiar, e a mulher, como dona de casa, para melhorar as condições de vida familiar. Não tardou muito para que a juventude rural também fosse incorporada nos discursos dos agentes encarregados do desenvolvimento rural e nas políticas modernizadoras da agricultura, com o estabelecimento de diretrizes específicas para os trabalhos com esse grupo de idade, conforme registros documentais da ABCAR (1967a). Assim, segundo Silva (2001), os jovens precisavam ser integrados em instituições específicas de socialização a fim de receberem orientações dos agentes de desenvolvimento rural. Instituíram-se, então, sob a ingerência da ABCAR, os clubes juvenis, denominados Clubes $4 \mathrm{~S}$, cujos princípios metodológico-educacionais seguiam os moldes dos Clubes $4 \mathrm{H}$ criados nos Estados Unidos. ${ }^{3}$ Otero e Selis (2016), com base em estudos da Revista Extensión en las Américas, afirmam que os

\footnotetext{
${ }^{2} \mathrm{O}$ crédito rural supervisionado destinava recursos para investir nas atividades produtivas e na melhoria das condições do lar de pequenos e médios agricultores mediante um plano de trabalho elaborado pelos agrônomos e assistentes sociais vinculados às instituições de extensão rural. Após a definição do plano, a família rural beneficiária recebia supervisão da aplicação do crédito rural e orientação técnica dos agentes de extensão rural. Ambos os instrumentos de políticas públicas combinavam "ajuda técnica e financeira" no esforço de promover mudanças nos padrões produtivos, nos hábitos e nos costumes das famílias rurais (FIGUEIREDO, 1984; RODRIGUES, 1997). Sob essa orientação, segundo Queda (1987), a extensão rural cumpria importante papel na "anunciação da modernização da agricultura" no Brasil.

${ }^{3}$ Segundo dados da Fundação Ford (1962), no início da década de 1960, mais de 70 países haviam instituído os clubes juvenis rurais aos moldes dos Clubes $4 \mathrm{H}$, criados nos Estados Unidos. Tal expansão é um indicativo dos investimentos econômicos e sociais para internacionalizar os modelos de organização social da juventude rural.
} 
serviços de extensão rural, institucionalizados no período do pós-guerra em países latino-americanos, foram fortemente influenciados pelos Estados Unidos, não somente pelo acúmulo nas experiências institucionais e nas políticas de desenvolvimento rural, mas, sobretudo, por razões econômicas e geopolíticas e relacionadas ao temor do avanço do socialismo em países latino-americanos. $\mathrm{Na}$ organização dos serviços de extensão rural na América Latina, segundo Otero e Selis (2016, p. 54), "a metodologia, os objetivos, os destinatários e as estratégias foram adotados quase linearmente, sendo um claro exemplo do lugar hegemônico que ocupava Estados Unidos, fundamentalmente relacionado ao caminho a seguir para o êxito do desenvolvimento rural."

Sob essa matriz, no Brasil, os agentes de extensão rural passaram a mediar a criação de grupos de jovens rurais. O primeiro Clube 4S foi criado em 1952 e, a partir daí, os investimentos na institucionalização da juventude em clubes rurais foram significativos, considerando-se o crescimento numérico de clubes e de jovens afiliados. ${ }^{4} \mathrm{O}$ trabalho com grupos de jovens, conforme registros documentais publicados pela ABCAR entre 1966 e 1970, estava ancorado no desenvolvimento de projetos agrícolas e domésticos, observando-se as particularidades das divisões sexuais do trabalho nas populações rurais. Os projetos propostos aos jovens podiam ser individuais ou grupais, sendo que, para os rapazes, destinavam-se atividades relacionadas aos cultivos e criações de interesse mercantil, enquanto que as moças recebiam orientação para o cultivo de hortaliças, processamento de alimentos, corte e costura, bordado, confecção de artesanatos, puericultura, dentre outras atividades consideradas apropriadas para o sexo feminino. Os clubes agrícolas constituíam-se em meios facilitadores da capacitação dos jovens rurais, com vistas ao aperfeiçoamento dos métodos de produção, aumento dos rendimentos nas atividades agrícolas, melhorias nas condições de vida e formação de futuros agricultores e donas de casa, para torná-los aptos aos modos e exigências da agricultura moderna.

Contudo, recursos financeiros e tecnológicos tornaram-se imprescindíveis no desenvolvimento de projetos com a juventude rural. Plaza (1962), em documento organizado pela Fundação Ford, relata que, nos primórdios dos trabalhos com jovens rurais, os recursos financeiros eram garantidos, em parte, pelos pais de jovens rurais afiliados em clubes e, em parte, por empresários organizados em torno do Comitê Nacional de Jovens Rurais. ${ }^{5}$ Essa instituição era constituída por grandes corporações empresariais, de capital internacional e nacional, vinculadas a bancos, indústrias, comércio e serviços, com o objetivo comum de incentivar os clubes de jovens rurais com a oferta de diferentes produtos e serviços.

$\mathrm{Na}$ realidade, os setores empresariais afiliados ao Comitê tinham clareza da importância de criar necessidades de consumo entre as gerações juvenis rurais para ampliar a circulação de mercadorias, bens e serviços e, ao mesmo tempo, aumentar a produção de matéria-prima para o processamento agroindustrial. Com estratégias diversas, os empresários vinculados a esse Comitê interferiam dentro dos

\footnotetext{
${ }^{4}$ Sucessivos documentos publicados pela ABCAR, por mim pesquisados, indicavam o crescimento de jovens institucionalizados em Clubes 4S: em 1953, contabilizavam-se 29 clubes juvenis e 645 afiliados; em 1969, somavam-se 3.604 clubes juvenis e 80.000 jovens sócios (ABCAR, 1966-1970).

${ }_{5}^{5}$ As principais empresas patrocinadoras dos clubes juvenis rurais, segundo sucessivos relatos da ABCAR, eram: Banco Bradesco, Banco Itaú-América, Banco Brasileiro do Lar, Massey Ferguson do Brasil, Ford Motors do Brasil, SOTREQ S/A Tratores e Equipamentos, Esso Brasileira de Petróleo, Sementes Horticeres, Sementes Agroceres, Associação Nacional para a Difusão de Adubos (ANDA), Manah, Copas, International Minerals \& Chemical Corporation (IMC), Biagro Velsicol, Union Carbide, Cia Auxiliar de Empresas de Mineração (CAEMI), Arbor-Acres Avicultura, Squibb Indústria Química S/A, Cargil Agrícola, Nestlé, Refinações de Milho Brasil, Sears Roebuck, Mesbla S/A, Singer Sewing Machine, Produtos Alimentícios Fleischmann \& Royal, Coca-Cola refrescos, IBM, dentre outras (ABCAR, 1966-1970).
} 
programas dirigidos à juventude rural com os interesses de ampliar suas influências econômicas e políticas no espaço rural. Ao mostrarem-se "amigas" dos clubes de jovens rurais, os empresários pretendiam construir os futuros produtores e consumidores de mercadorias com vistas a integrá-los nas cadeias produtivas agroindustriais que se instalavam em território brasileiro. Portanto, empresários e agentes dos serviços de extensão rural firmavam parcerias para propor e desenvolver trabalhos orientados para os jovens rurais. As parceiras entre instituições públicas e privadas tornavam-se convenientes no desenvolvimento de ações educativas junto aos jovens rurais, uma vez que havia consensos quanto à importância de formar os futuros tomadores de crédito rural e usuários das tecnologias e dos serviços modernos.

A objetivação das ações extensionistas demandava máquinas, equipamentos, insumos químicos, sementes e animais, que nem sempre eram disponibilizados no tempo, na quantidade e na qualidade idealizados pelos agentes de extensão rural. A escassez de recursos técnicos e financeiros constituía-se um obstáculo ao desenvolvimento de trabalhos com a juventude afiliada aos clubes rurais. Surgia, então, a necessidade de instituir formas creditícias para os jovens rurais a fim de criar condições para o aprendizado do uso das novas tecnologias e práticas culturais. A experiência norte-americana de crédito para a juventude também serviu de referência para institucionalização da modalidade de crédito juvenil no Brasil, assim como em diversos países do continente latino-americano.

Portanto, a juventude rural no Brasil, enquanto categoria social vinculada a instituições e políticas de desenvolvimento rural, foi uma construção da sociedade industrial em seu propósito de produzir gerações juvenis adequadas, técnica e ideologicamente, tanto para o aumento da produção agrícola em bases tecnológicas modernas quanto para o consumo de bens e serviços industriais (MARIN, 2009).

\section{CRÉDITO JUVENIL: INVESTIMENTOS PARA A PRODUÇÃO DE JOVENS RURAIS MODERNOS}

A criação de uma modalidade de crédito agrícola, especificamente orientado para jovens rurais, representou esforços sociais para produzir uma juventude moderna e integrada em instituições e políticas desenvolvimentistas. As bases legais e burocráticas para a institucionalização do Crédito Juvenil, segundo documento publicado pela Fundação Ford (1960, p. 149-151), foram estabelecidas no escopo do Projeto 17 do ETA (Escritório Técnico de Agricultura Brasil - Estados Unidos), no ano de 1956. Esse projeto tinha como objetivo modernizar a produção leiteira no município de São José, estado de Santa Catarina, por meio de contratos firmados entre os bancos, as instituições de extensão rural, a família rural, o clube juvenil e o jovem rural. ${ }^{6}$ O Projeto 17 previa, em suas cláusulas contratuais, o fornecimento de novilhas da raça holandesa ao clube juvenil, com um preço previamente estabelecido. O presidente do clube juvenil, por sua vez, comprometiase em repassar os animais aos sócios, arrecadar as prestações dos sócios beneficiários e fazer o depósito em uma conta bancária movimentada pelo tesoureiro do clube e pelo extensionista rural. O segundo contrato era assinado pelo presidente do clube rural, pelo jovem e pelo seu pai. Por meio desse contrato, o presidente do

\footnotetext{
${ }^{6}$ Os extensionistas rurais, segundo documento publicado pela Fundação Ford (1960), constataram que o rebanho bovino de leite de Santa Catarina era formado por animais nativos de baixa produtividade e tratados com técnicas inadequadas. A fim de promover mudanças nesse panorama, os extensionistas mobilizaram os jovens rurais para melhorar a genética do rebanho, adotar de práticas modernas de manejo e alimentação e aumentar a produção de leite.
} 
clube vendia as novilhas aos sócios em até trinta prestações mensais. O animal não podia ser comercializado antes do ressarcimento da dívida, salvo na concordância do extensionista. Em caso de atraso no pagamento de até três prestações, a novilha era recolhida em favor do clube, que tinha a prerrogativa de vendê-lo para outro jovem afiliado ao clube. Os jovens contratantes também assumiam compromissos de construir abrigo para o animal, fornecer-Ihe alimentação adequada, ministrar-Ihe as recomendações higiênico-sanitárias e, quando solicitado, deviam participar das exposições agropecuárias. A não observância das cláusulas contratuais podia implicar advertências e recolhimento da novilha em favor do clube, que, logo, era repassada para outro jovem associado (FUNDAÇÃO FORD, 1960).

Essa experiência pioneira de Crédito Juvenil tecia uma rede de relações contratuais entre o jovem rural e sua família, o clube de pertença, a equipe de extensão rural e o sistema bancário. Pessoas e instituições interligavam-se, por meio de contratos, com o objetivo modernizar as atividades produtivas de leite daquele município catarinense. Nessas relações contratuais creditícias, os jovens rurais permaneciam tutelados tanto pelos bancos, que determinavam as condições de pagamento e valores das prestações, quanto pelos técnicos, que orientavam a adoção de novas tecnologias e de novos procedimentos técnicos. Os contratos determinavam a adoção de tecnologias modernas - animais geneticamente melhorados, rações, suplementos minerais e produtos veterinários -, que implicavam a inserção dos jovens rurais na órbita do consumo de produtos industriais. Os jovens rurais integravam-se como consumidores, contribuindo para a ampliação do mercado de insumos e tecnologias produzidas pelas indústrias que se estabeleciam no país. Integravam-se, também, como produtores mercantis na medida em que contribuíam para o aumento da produção de leite e comercialização dos excedentes para as indústrias de laticínios que já se instalavam na região.

A experiência de Crédito Juvenil foi estendida para diversos municípios e atividades produtivas do estado de Santa Catarina. Em pouco tempo, outros estados da Federação também institucionalizaram essa modalidade financiamento creditício. No Brasil, o estado de Minas Gerais foi pioneiro na organização de Clubes Juvenis e na criação da modalidade de crédito rural juvenil, com recursos governamentais e não somente provenientes de projetos internacionais ou de setores empresariais. A institucionalização do crédito juvenil ocorreu no ano de 1961, numa parceria firmada entre a Associação de Crédito e Assistência Rural (ACAR/MG) e a Caixa Econômica do Estado de Minas Gerais. Publicações da Fundação Ford (1960; 1962), com propósitos de relatar os avanços dos investimentos na institucionalização da juventude rural, informava que diversos países latino-americanos disponibilizaram recursos financeiros para jovens afiliados aos clubes rurais. Em um documento publicado pela Fundação Ford, João Napoleão de Andrade, então presidente da ABCAR, relatou um panorama promissor do Crédito Juvenil no cenário brasileiro e latino-americano:

Em toda a América Latina, os pequenos empréstimos feitos a jovens associados aos Clubes da Juventude Rural estão constituindo um novo elemento propulsor na vigorosa campanha de aumento da produtividade agrícola e na melhoria dos padrões de vida das comunidades latino-americanas. No Estado de Minas Gerais, no Brasil, estão sendo aplicados na concessão de financiamento a projetos de aves, produção leiteira e milho híbrido, que se desenvolvem em Clubes 4-S. Programas similares de crédito estão sendo promovidos no Chile, Peru, Venezuela, Uruguai, Paraguai, El Salvador e outros países. Os empréstimos feitos a membros de Clubes da 
Juventude Rural revelaram um significativo progresso no trabalho educativo através da Extensão Rural, pois constituem um valioso elemento de apoio e estímulo aos jovens, no sentido de aplicarem mais e melhor os ensinamentos recebidos de especialistas em técnicas agrícolas, em trabalhos manuais e em economia doméstica (ANDRADE, 1962, p. 94).

O plano de expansão do crédito juvenil foi arquitetado por organizações internacionais, especialmente a AIA, Fundação Ford e FAO, mas muito aclamado pelos empresários, que tinham clareza da relação direta entre crescimento de recursos financeiros e o aumento do consumo de serviços e produtos industriais, bem como o aumento do volume da produção agrícola mercantil. Indubitavelmente, o crescimento do volume de recursos financeiros possibilitava a maior circulação de mercadorias tanto de uso agrícola e doméstico quanto de matéria-prima para processamento industrial e alimentos para a população urbana, contribuindo para o desenvolvimento do capital.

Os agentes sociais vinculados ao poder público, por sua vez, percebiam o Crédito Juvenil como um instrumento fundamental para a formação de futuros e modernos agricultores e donas de casa, em conformidade com a modernização da agricultura. As normativas do Crédito Juvenil foram delineadas exatamente para a construção de tipos ideais de jovens rurais. De acordo com as normativas, registradas por João Napoleão de Andrade, então presidente da ABCAR, o Crédito Juvenil estava restrito aos jovens sócios ativos de um Clube 4-S, residentes no meio rural e filhos de agricultores, que tinham a autorização do pai ou tutor, a quem cabia a assinatura do contrato e das notas promissórias, e comprometidos a "seguir cuidadosamente um guia de projeto técnico preparado pelos especialistas de extensão, de maneira a utilizar as técnicas apropriadas e a aprender com a prática". Ademais, para receber empréstimos, os jovens e os clubes deviam ter "boa reputação" e, uma vez concedidos, os recursos financeiros não podiam ser transferidos de sócio ou de clube, nem mesmo os projetos financiados podiam ter seus objetivos redefinidos. Os projetos de financiamento eram elaborados pelos técnicos de extensão, com aprovação do jovem contratante, de seus pais e de clube de pertença. Na sequência, o projeto era encaminhado para as agências bancárias habilitadas à concessão de crédito juvenil e, por fim, os técnicos extensionistas supervisionavam a aplicação dos recursos do financiamento e a observância das recomendações técnicas (ANDRADE, 1962, p. 98).

Tais procedimentos de enquadramento creditício tinham duas implicações fundamentais. A primeira era a restrição do número de jovens rurais habilitados para contrair o Crédito juvenil, pois poucos tinham condições sociais para atender tantas exigências normativas. Dessa forma, o crédito rural restringiu-se aos jovens rurais filhos de proprietários de terras, que apresentavam melhores condições econômicas, exerciam alguma forma liderança dentro dos grupos juvenis rurais e apresentavam melhores condições de receptividade e liderança social para efeitos demonstrativos das ações de extensão rural. Os jovens rurais beneficiários de financiamentos eram cuidadosamente selecionados pelos extensionistas rurais para serem destinados a representar os tipos ideais para a juventude rural: modernos, sócios de clubes juvenis, adotantes de tecnologias e inseridos no mercado produtivo e financeiro.

A segunda implicação prática era que o Crédito Juvenil engendrava poderosos mecanismos de controle social e de produção da tutela dos jovens rurais, que se fundamentava desde o critério moral seletivo da "boa reputação", passando pela obediência dos critérios de enquadramento normativo do financiamento e confluía na aceitação das orientações técnicas previstas no plano de 
desenvolvimento definido pelos extensionistas rurais. Naquele contexto, os agentes mediadores comprometidos com a modernização muito criticavam o autoritarismo das gerações dos pais e sua incapacidade de transmitir conhecimentos modernos, uma vez que eram orientados pelo tradicionalismo e pela resistência às mudanças sociais. $O$ enquadramento institucional, representado nos Grupos de Jovens e na política de Crédito Juvenil, constituía-se significativo investimento para subtrair o domínio paternal familiar e, ao mesmo tempo, transferir poderes aos agentes de desenvolvimento. Ao ingressarem naqueles espaços institucionais, os jovens rurais passavam a ser dirigidos pelos extensionistas rurais no sentido da objetivação da modernização da agricultura.

Os agentes de extensão rural conferiam ampla publicidade para os feitos realizados em torno do crédito agrícola junto aos jovens rurais. No entanto, em termos da realidade empírica, algumas fontes documentais por mim pesquisadas indicam que o seu alcance numérico não foi significativo tanto no que se refere ao número de contratos firmados quanto ao montante do volume de crédito contraído por contrato. Para dar início ao programa de crédito juvenil, em 1961, o governo de Minas Gerais disponibilizou um volume de $\operatorname{Cr} \$ 1.000 .000,00$ - o que, na época, equivalia, aproximadamente, a US\$ $5.500,00$ - para projetos de milho híbrido, avicultura e bovinocultura de leite (ANDRADE, 1962, p. 98). No ano de 1966, a ACAR - Goiás, em convênio firmado entre o Banco do Estado de Goiás e o Comitê Nacional de Clubes 4-S, recebeu um montante de $\operatorname{Cr} \$ 4.800 .000,00$ (4,8 milhões de cruzeiros), provenientes de uma verba de Cr\$100.000.000,00 (100 milhões de cruzeiros), concedida pela United States Agency for International Development (USAID), para estimular o crédito rural juvenil nos estados que contavam com serviços de extensão rural vinculados ao sistema oficial de extensão rural (ABCAR, 1966a). Em 1967, no Rio Grande do Norte, o Banco do Estado e a ANCAR - RN firmaram um convênio que disponibilizou NCr\$25.000,00 para 500 empréstimos da linha crédito juvenil (ABCAR, 1967b). De acordo com relato da ABCAR, em 1967, o crédito juvenil operava em oito estados da Federação e o montante dos recursos disponibilizados era crescente, tanto em volume quanto em operações bancárias:

\begin{abstract}
a ampliação do crédito rural juvenil em 1966 se expressa por 384 contas abertas a sócios 4-S, no montante de NCr\$ $87.349,00$. Com isso o número de empréstimos ativos, no final do exercício, elevava-se a 844, no valor total de NCr\$ $152.862,00$, nos oito Estados em que os serviços de Extensão operam com esta modalidade de crédito educativo. Dentre eles, Minas Gerais tem absoluta predominância, obtendo $81 \%$ do número total de empréstimos ativos e quase $70 \%$ do respectivo valor (ABCAR,1967c, p. 18).
\end{abstract}

Nota-se que o crédito juvenil estava concentrado em alguns estados brasileiros, contemplava poucos jovens e clubes rurais. Documentos levantados em publicações da ABCAR oferecem uma visão do montante e dos fins dos projetos de crédito financeiro concedidos aos jovens rurais. Em Cachoeiro do Itapemirim, a ABCAR (1966b) anunciava o primeiro empréstimo do crédito juvenil do estado do Espírito Santo, no valor de $\mathrm{Cr} \$ 46.250,00$, assinado pelo jovem Eurico Gonzaga Agrizzi, para o cultivo de 2.500 metros quadrados de milho híbrido, com reembolso no prazo de oito meses. Com o dinheiro, o jovem devia comprar as sementes, fazer a correção da acidez do solo, a adubação química, o plantio em curvas de nível, observar o espaçamento entre as plantas e realizar outros procedimentos técnicos recomendados. No ano de 1967, a ABCAR (1967b) relatava que o estado da Paraíba recebeu um montante de NCr\$3.179,08, concedidos pela USAID, para 22 
projetos de criação de cabras, conduzidos por jovens rurais. Com um total de NCr\$ 151,38 , os jovens beneficiários destinavam o recurso para a construção de abrigo e aquisição dos animais, ração e medicamentos. Também 1967, o governo do estado do Rio Grande do Norte distribuiu NCr\$25.000,00 em 500 empréstimos para jovens rurais, para aplicação em projetos de algodão herbáceo, com um teto de $\mathrm{NCr} \$$ 70,00 , milho híbrido com até $\mathrm{NCr} \$ 50,00$ e suínos com um limite de $\mathrm{NCr} \$ 80,00$ (ABCAR, 1967d).

Pelo exposto, depreendo que os valores alocados em cada projeto de financiamento não eram elevados, mas o bastante para principiar a implantação de pequenas lavouras ou criações em bases modernas, com fins de produzir modelos de atividades produtivas modernas objetivadas por jovens modernos e organizados pelas instituições de extensão rural. Com tais intentos, eram produzidos modelos, tanto de jovens rurais quanto de atividades produtivas, com a expectativa de serem adotados por outros jovens, gerando mudanças subsequentes nas comunidades rurais, na região e no país. Por tanto, as experiências com o crédito agrícola representavam significativos investimentos sociais, não somente para encorajar a adoção de novas tecnologias e facilitar os trabalhos de extensão rural, mas, sobretudo, para criar referências para as coletividades de jovens rurais.

\section{CRÉDITO JUVENIL: A PRODUÇÃo DE MODELOS IDEAIS PARA A JUVENTUDE RURAL}

Para os órgãos responsáveis pela extensão rural, a juventude era conceituada como "a faixa da população que se encontra na fase de transição entre a infância dependente e o completo domínio das faculdades do homem adulto", enquanto a juventude rural era a "população jovem cujos interesses, necessidades e subsistência estejam relacionados com atividades do meio rural, sem considerar sua localização" (ABCAR, 1969a, p. 17). Sob esse prisma, a noção de juventude rural estava associada a uma fase da vida, que oscilava entre a dependência e a emancipação pessoal, daqueles indivíduos que viviam no meio rural ou trabalhavam na agricultura e encontravam-se na faixa entre 10 e 25 anos de idade.

Muito além de uma fase do ciclo da vida, as representações sobre a juventude rural estavam associadas ao futuro, ao progresso, ao desenvolvimento e às mudanças sociais. Na condição de pessoas em fase especial do ciclo da vida, os jovens podiam realizar importantes mudanças sociais na medida em que estavam mais predispostos a adotar novas tecnologias e internalizar conhecimentos e concepções modernas de mundo. Assim, o trabalho educativo com a juventude rural visava adequá-la ao desenvolvimento da agricultura na expectativa de mudar a família por meio dos filhos jovens e, por extensão, modernizar a sociedade por meio da juventude. Nesse período, eram comuns os argumentos sobre as dificuldades em mudar as mentalidades e os hábitos da população rural adulta, enquanto se decantava a pré-disposição da juventude para a promoção de mudanças técnicas e sociais. A partir da juventude rural, os agentes da modernização esperavam formar uma população rural predisposta a incorporar novas ideias e tecnologias e, por consequência, mudar os comportamentos e as concepções de mundo dos adultos.

Para tanto, em torno do crédito agrícola juvenil, agentes vinculados às instituições desenvolvimentistas construíram imagens do jovem rural moderno e integrado em instituições e programas de desenvolvimento social. Como indica Feixa (2006), ao lado da criação de instituições e de programas juvenis, são construídas imagens culturais para representar o dever ser jovem nas diferentes sociedades. As imagens culturais estão associadas à subjetividade e fazem referências aos valores, símbolos, atributos e ritos associados aos jovens. Sem 
desconsiderar a possibilidade de os jovens produzirem imagens culturais, para efeitos deste artigo, interessa compreender as imagens culturais ensejadas pela política de crédito rural destinada à juventude rural no contexto em apreciação.

O Crédito Juvenil, como efeito pedagógico, contribuiu para a produção de jovens adotantes de tecnologia e campeões de produtividade para configurarem como líderes da juventude rural. Jovens rurais exemplares que, pelo seu comprometimento moral com a realização do milagre da modernização da agricultura brasileira, deviam ser invejados e seguidos por todos os jovens rurais.

Por meio do crédito juvenil, os agentes sociais encarregados pela promoção do desenvolvimento rural buscavam construir modelos ideais de jovens dentro dos clubes rurais e das comunidades rurais, com a valorização das aptidões para a adoção de tecnologias e procedimentos administrativos modernos, sob as condições pré-determinadas pelos agentes dos serviços de extensão rural e do sistema de crédito rural juvenil. Sobre os jovens contratantes de empréstimos bancários e experimentadores de tecnologias modernas, estavam depositadas as expectativas de constituir os exemplos a serem seguidos pelos demais jovens rurais, pela família e pelos membros das comunidades em que viviam. Eles formavam os grupos de "jovens inovadores" nos processos de difusão de tecnologias, em conformidade com os referenciais teóricos propostos por Everet Rogers (1974).

Para exemplificar os esforços da constituição de tipos ideais para a juventude rural, vale relatar o caso do jovem Ivanor, de Antonio Prado, estado do Rio Grande do Sul. Em 1966, esse jovem obteve um financiamento no valor de Cr\$ 50 mil com o objetivo de instalar um aviário, comprar 100 pintos de raças geneticamente melhoradas, ração balanceada, medicamentos, além de adotar novas técnicas de manejo dos animais, que, em seu conjunto, constituíam o pacote tecnológico recomendado pelos extensionistas. Com essa experiência, segundo relato da ABCAR (1966c, p. 7-8):

os vizinhos e amigos de Ivanor olham com interesse o seu trabalho. Outros rapazes e alguns colonos começam a seguiIhe o exemplo, partindo de precárias criações de fundo de quintal para uma avicultura que constituiu negócio compensador naquela zona, pois frangos de corte e ovos têm colocação garantida, a bons preços, na cidade de Antonio Prado.

No caso relatado, o jovem representava o progresso da região e a promoção de mudanças sociais, que serviam de referências aos outros indivíduos quanto às possibilidades acenadas pelas transformações nas bases técnicas e pelo aprofundamento da integração mercantil. Por essas razões, os discursos dos agentes sociais vinculados às empresas privadas e às agências públicas de desenvolvimento rural produziam as ideias do que devia ser jovem rural num contexto de modernização. Nesse sentido, os conteúdos dos registros documentais da Revista da ABCAR são elucidativos dos investimentos de criação dos estilos ideais juvenis quando afirmam que: "os jovens constituem potencial da transformação da agricultura" (ABCAR, 1969a, p. 9), "a alta produtividade vem com os jovens" (ABCAR, 1968), "os jovens rurais participam da revolução tecnológica na agricultura" (ABCAR, 1969b, p. 10) e que o significado dos trabalhos com os jovens rurais "tem importância para a agropecuária nacional, não somente porque prepara os futuros agricultores do Brasil, capacitando-os para obterem maior rendimento com a exploração da terra, mas principalmente porque, através deles, pode-se influir na mudança de métodos de produção agropecuária e na melhoria das condições de 
bem-estar da família rural" (ABCAR, 1969c, p. 11). Ainda, trazem que cada jovem que participa do clube "derruba antigas crenças, varre velhos hábitos e abre caminho para a aceitação de novas idéias capazes de mudar o quadro econômico e social da terra em que nasceu" (ABCAR, 1968, p. 15).

Esses registros documentais deixam claro que o jovem ideal era aquele que se encontrava afiliado a um clube juvenil, contratava financiamentos agrícolas, aceitava as orientações dos extensionistas e contribuía para o amplo projeto de realização do milagre da modernização da agricultura. Melhor ainda era o jovem que conquistava o prêmio de "Campeão de produtividade", título honorífico conferido anualmente para o reconhecimento do mérito daqueles jovens que atingiam melhores níveis produtivos em diferentes modalidades, em concursos ${ }^{7}$ que se desencadeavam nas esferas regionais, estaduais, nacional e interamericana. Não é por acaso que os eventos nacionais de entrega dos prêmios tinham grande publicidade nos meios de comunicação e contavam com a presença de representantes de órgãos de extensão rural, empresários e autoridades políticas, inclusive de presidentes da República (ABCAR, 1967e). Os jovens campeões podem ser considerados uma metáfora de uma agricultura brasileira, que devia ser moderna tecnologicamente e com altos níveis de produtividade. Podem, também, representar metáfora de uma sociedade autoritária que concedia recompensas àqueles que se enquadravam no modelo de modernização conservadora, implantada pelo Estado e com o apoio de grandes empresas de capital nacional e multinacional.

\section{CONSIDERAÇÕES FINAIS}

O crédito juvenil, instituído no contexto da modernização da agricultura brasileira, contribuiu para criar as condições sociais de enquadramento dos jovens para o uso de tecnologias modernas e para a administração dos recursos financeiros com o propósito de incorporá-los na órbita mercantil, como consumidores de tecnologias e serviços modernos e produtores de alimentos e de matérias-primas para transformação industrial. A política do crédito juvenil criava novas formas de integração dos jovens em um conjunto de instituições imbuídas com a construção social de gerações juvenis adequadas aos propósitos modernizantes.

Assim, crédito juvenil e instituições juvenis somavam-se para romper os tradicionais sistemas de produção e de transmissão dos conhecimentos estabelecidos pelas famílias e comunidades rurais, com a transferência de poderes para os extensionistas e ao sistema bancário acerca dos investimentos a serem realizados nas propriedades, das condições técnicas produtivas e da forma de gestão das unidades produtivas. De certa forma, os extensionistas ampliavam seus domínios, uma vez que detinham a posse de conhecimentos, tecnologias e procedimentos administrativos, então considerados modernos, enquanto gestionavam a redução da autoridade e autonomia dos pais na transmissão de conhecimentos às gerações juvenis.

Paralelamente, criavam-se novas imagens juvenis, cujo ideal girava em torno do jovem moderno, integrado em instituições, contratante de crédito financeiro, promotor de mudanças tecnológicas e sociais e comprometido com o futuro do país. Em suma, o jovem rural ideal era o jovem campeão de produtividade. Por tais

\footnotetext{
7 Entre a década de 1960 e início da década 1980, período de intensos trabalhos com Clubes 4S, a juventude rural foi envolvida em diversos concursos para premiar os jovens que se destacavam nos projetos de produtividade e projetos sociais. Como desdobramento, os jovens campeões nacionais eram encaminhados para representar o Brasil nos concursos interamericanos da juventude rural a fim de competirem com outros jovens da América Latina e América do Norte.
} 
razões, o Crédito Juvenil foi um instrumento utilizado pelos agentes de desenvolvimento para a formação de jovens modernos para representá-los como modelos aos coletivos da juventude rural brasileira.

\section{REFERÊNCIAS}

ABCAR. Extensão Rural - Revista da Associação Brasileira de Crédito e Assistência Rural. a. 1 - 5, n. 1 - 60, 1966 -1970.

ABCAR. Crédito rural juvenil passa a apoiar Clubes 4-S de Goiás. Extensão Rural, a. 1, n. 2, fev., 1966a.

ABCAR. ACAR-ES e ANCAR-BA expandem operações com crédito juvenil. Extensão Rural, a. 1, n. 3, mar., 1966 b.

ABCAR. Quatroessista lança semente do progresso avícola. Extensão Rural, a. 1, n. 2, fev., 1966c.

ABCAR. Diretrizes para o trabalho de extensão rural com a juventude. Rio de Janeiro: ABCAR, 1967a.

ABCAR. Banco do Rio Grande do Norte inicia operações com crédito juvenil. Extensão Rural, a. 2, n. 16, abr., 1967b.

ABCAR. Juventude rural: flagrantes do crédito juvenil. Extensão Rural, a. 2, n. 17, maio., 1967c.

ABCAR. Projeto Cabra recebe crédito de acima de NCr\$ 3 mil. Extensão Rural, a. 2, n. 17, maio., 1967d.

ABCAR. Presidente Costa e Silva exalta a significação dos Clubes 4-S. Extensão Rural, a. 2, n. 21, set., 1967e.

ABCAR. Alta produtividade vem com os jovens. Extensão Rural, a. 3, n. 32, ago., 1968.

ABCAR. Jovens constituem potencial de transformação da agricultura. Extensão Rural, a. 4, n. 40, abr., 1969a.

ABCAR. Jovens rurais participam da revolução tecnológica na agricultura. Extensão Rural, a. 4, n. 45, set., 1969b.

ABCAR. Integração da juventude no processo de desenvolvimento. Extensão Rural, a. 4 , n. 43, jul., 1969c.

ANDRADE, J. N. Participação da juventude no desenvolvimento. Extensão Rural, a. 3, n. 25, jan., 1968.

ANDRADE, J. N. Pequenos empréstimos dão estímulos ao trabalho dos clubes da juventude rural. FUNDAÇÃO FORD (Org.). Juventude rural das Américas. Dearborn: Ford Motor Company, 1960. 
BOURDIEU, P. A juventude é apenas uma palavra. Questões de sociologia. Rio de Janeiro: Editora Marco Zero Ltda., 1983.

CELLARD, C. A análise documental. In: POUPART, J.; et al. (Orgs). A pesquisa qualitativa: enfoques epistemológicos e metodológicos. Petrópolis: Vozes, 2010, p. 297-316.

FEIXA, C. P. A construção histórica da juventude. In: CACCIA-BAVA, A. et al. Jovens na América Latina. São Paulo: Escrituras Editora, 2004.

FEIXA, C. P. De jóvenes, bandas y tribus. Barcelona: Editorial Ariel, 2006.

FEIXA, C. P. La joventut com a metáfora. Barcelona: Secretaria General de Joventut, 1993.

FIGUEIREDO, R. P. Extensão rural no Brasil: novos tempos. Revista Brasileira de Tecnologia, Brasília, v. 15, n. 4, jul./ago., p. 19-25, 1984.

FONSECA, M. T. L. A extensão rural no Brasil: um projeto educativo para o capital. São Paulo: Loyola, 1985.

FUNDAÇÃO FORD (Org.). Juventude rural das Américas. Dearborn: Ford Motor Company, 1962.

GRAZIANO DA SILVA, José. A nova dinâmica da agricultura brasileira. Campinas: UNICAMP, 1998.

MACHADO, G. O. D.; RIBEIRO, J. P. Filosofia do crédito rural supervisionado e sua relação com os serviços de extensão. VIEIRA, J. A.; CABRAL, J. I. (Orgs). Crédito rural supervisionado no Brasil: reunião de trabalhos técnicos da $A B C A R$ e suas afiliadas. Rio de Janeiro: SAI-ETA-ABCAR, 1960.

MARIN, J. O. B. Juventud rural: una invención del capitalismo industrial. Estudios Sociológicos, México, v. 27, n. 80, p. 619-653, 2009. Disponível em: <http://www.redalyc.org/pdf/598/59820676009.pdf>. Acesso em: 22 dez. 2016.

MARTINS, J. S. Capitalismo e tradicionalismo: estudos sobre as contradições da sociedade agrária no Brasil. São Paulo: Pioneira, 1975.

NETO, W. G. Estado e agricultura no Brasil: política agrícola e modernização econômica brasileira. 1960-1980. São Paulo: Hucitec, 1997.

NEVES, D. P. As políticas agrícolas e a construção do produtor moderno. Cadernos de Difusão de Tecnologias. Brasília, v. 4., n. 3, p. 343-367, nov./dez., 1987. Disponível em: <https://seer.sct.embrapa.br/index.php/cct/article/view/9172/5211>. Acesso em: 07 fev. 2017.

OLIVEIRA, M. M. As circunstâncias da criação da extensão rural no Brasil. Cadernos de Ciência \& Tecnologia, Brasília, v. 16, n. 2, p. 97-134, 1999. Disponível em: <https://seer.sct.embrapa.br/index.php/cct/article/view/8898/5020>. Acesso em: 10 mar. 2017. 
OTERO, J.; DARDO. S. La Revista "Extensión en las Américas". Influencia de los EEUU en los servicios de extension rural latinoamericanos. Extensão Rural, Santa Maria, v. 23, n. 1, jan./mar., p. 42-57, 2016. Disponível em: <https://periodicos.ufsm.br/extensaorural/article/view/17359/pdf>. Acesso em: 01 jun. 2017.

PLAZA, G. Comitês cívicos fortalecem os clubes da juventude rural. FUNDAÇÃO FORD (Org.). Juventude rural das américas. Dearborn: Ford Motor Company, 1962.

QUEDA, O. Extensão rural no Brasil: da anunciação ao milagre da modernização agrícola. 1987. 201p. Tese (Livre Docência) - Escola Superior de Agricultura "Luiz de Queiroz", Piracicaba, 1987.

RODRIGUES, C. M. Conceito de seletividade de políticas públicas e sua aplicação no contexto da política de extensão rural no Brasil. Cadernos de Ciência \& Tecnologia, Brasília, v. 14, n. 1, p. 113-154, 1997. Disponível em: <http://www.alice.cnptia.embrapa.br/bitstream/doc/87857/1/Conceitodeseletividade.p df>. Acesso em: 15 mar. 2017.

ROGERS, E. La comunicación de inovaciones: un enfoque transcultural. México: AID, 1974.

SEIFFERT, R. Q. Guerra Fria e estratégias ideológico-sociais da extensão rural (1946-1963). Boletim de Ciências Sociais, n. 46, jul./set., 1987.

SILVA, C. M. Discursos sobre a juventude rural participante de Clubes 4-S (19591977). Esboços - Revista do Programa de Pós-Graduação em História da UFSC; v. 9, n. 9, p 144-156, 2001. Disponível em: < https://periodicos.ufsc.br/index.php/esbocos/article/view/568/9840>. Acesso em: 28 jul. 2015.

SORJ, B. Estado e classes sociais na agricultura brasileira. Rio de Janeiro: Zahar Editores, 1980. 